\title{
Orodispersible Film Loaded with Enterococcus faecium CRL183 Presents Anti-Candida albicans Biofilm Activity In Vitro
}

\author{
Virgínia Barreto Lordello ${ }^{1}$, Andréia Bagliotti Meneguin ${ }^{1}$, Sarah Raquel de Annunzio ${ }^{1}$, Maria Pía Taranto ${ }^{2}$, \\ Marlus Chorilli ${ }^{1}$, Carla Raquel Fontana ${ }^{1, *}$ a and Daniela Cardoso Umbelino Cavallini ${ }^{1, *}$ (D) \\ 1 School of Pharmaceutical Sciences, Sao Paulo State University (UNESP), Rodovia Araraquara-Jaú, Km 01-s/n, \\ Campus Ville, Araraquara 14800-903, Brazil; virginialordello@gmail.com (V.B.L.); \\ andreia.meneguin@unesp.br (A.B.M.); sarinha_annunzio@hotmail.com (S.R.d.A.); \\ marlus.chorilli@unesp.br (M.C.) \\ 2 Reference Center for Lactobacilli (CERELA-CONICET), San Miguel de Tucumán, Chacabuco 145, \\ Tucumán T4000 ILC, Argentina; ptaranto@cerela.org.ar \\ * Correspondence: carla.fontana@unesp.br (C.R.F.); d.cavallini@unesp.br (D.C.U.C.)
}

check for updates

Citation: Lordello, V.B.; Meneguin, A.B.; de Annunzio, S.R.; Taranto, M.P.; Chorilli, M.; Fontana, C.R.; Cavallini, D.C.U. Orodispersible Film Loaded with Enterococcus faecium CRL183 Presents Anti-Candida albicans Biofilm Activity In Vitro. Pharmaceutics 2021, 13, 998. https://doi.org/10.3390/ pharmaceutics13070998

Academic Editor: Barbara Luppi

Received: 20 May 2021

Accepted: 16 June 2021

Published: 30 June 2021

Publisher's Note: MDPI stays neutral with regard to jurisdictional claims in published maps and institutional affiliations.

Copyright: (C) 2021 by the authors. Licensee MDPI, Basel, Switzerland. This article is an open access article distributed under the terms and conditions of the Creative Commons Attribution (CC BY) license (https:// creativecommons.org/licenses/by/ $4.0 /)$.

\begin{abstract}
Background: Probiotic bacteria have been emerging as a trustworthy choice for the prevention and treatment of Candida spp. infections. This study aimed to develop and characterize an orodispersible film (ODF) for delivering the potentially probiotic Enterococcus faecium CRL 183 into the oral cavity, evaluating its in vitro antifungal activity against Candida albicans. Methods and Results: The ODF was composed by carboxymethylcellulose, gelatin, and potato starch, and its physical, chemical, and mechanical properties were studied. The probiotic resistance and viability during processing and storage were evaluated as well as its in vitro antifungal activity against $C$. albicans. The ODFs were thin, resistant, and flexible, with neutral $\mathrm{pH}$ and microbiologically safe. The probiotic resisted the ODF obtaining process, demonstrating high viability $\left(>9 \log _{10} \mathrm{CFU} \cdot \mathrm{g}^{-1}\right.$ ), up to 90 days of storage at room temperature. The Probiotic Film promoted $68.9 \%$ of reduction in fungal early biofilm and $91.2 \%$ in its mature biofilm compared to the group stimulated with the control film. Those results were confirmed through SEM images. Conclusion: The probiotic ODF developed is a promising strategy to prevent oral candidiasis, since it permits the local probiotic delivery, which in turn was able to reduce $C$. albicans biofilm formation.
\end{abstract}

Keywords: probiotics; biofilm; anti-Candida activity; orodispersible films; Candida albicans; Enterococcus faecium

\section{Introduction}

It is well established that probiotics, which are defined as "living microorganisms that, when administered in adequate amount, confer a health benefits to the host" [1], can improve dysbiotic microbiota, regulate intestinal transit, neutralize carcinogens, promote vitamin synthesis and bile salt metabolism, reinforce gut barrier and the immune system, and directly antagonize and compete with pathogens [2]. Several studies have shown that specific probiotic strains have great potential for improving oral health, presenting anticariogenic activity, reduction of halitosis, and prevention of opportunistic infections, such as candidiasis, which are often present in immunocompromised individuals [3-7].

These pathogenic conditions are related to the formation and establishment of biofilms in the oral cavity. Infections caused by biofilms, especially fungal biofilms, are long-lasting and difficult to eliminate. Therefore, high doses of antifungals are often required, which promote serious adverse effects due to the similarity between host and fungal cells and lead to pharmacotherapy resistance [7-9].

Thus, alternative approaches for fungal infections must be searched, and prevention seems to be the best strategy. Our research group has demonstrated that Enterococcus faecium CRL 183, a proven safe potentially probiotic strain [10,11], was able to impair Candida 
albicans ATCC 90028 in vitro in up to $99.9 \%$ without losing its own viability. Researchers tested the interaction of fungus-probiotic in different proportions $(1: 1 ; 1: 10$, and 1:100), and even in its lowest concentration $\left(10^{7} \mathrm{CFU} \cdot \mathrm{mL}^{-1}\right)$, E. faecium CRL 183 impaired C. albicans viability in $97.12 \%$ (results awaiting publication). Those findings agree with several studies that show that C. albicans spp. supports the survival of Enterococcus spp., and this bacterium attenuates that fungus virulence and viability in polymicrobial infections through the secretion of proteases, bacteriocins, and lactic acid [10,12-16]. E. faecium CRL 183 was also able to inhibit the growth of Streptococcus mutans ATCC 25175, which is another important pathogen of the oral cavity [17].

One of the greatest challenges concerning probiotic products is to develop non-dairy alternatives focusing on local actions. These novel products should grant probiotic viability during processing and storage, should not alter product flavor or consistency and, on the oral cavity concern, should stay in the mouth long enough to release the probiotic [17-19].

An option that meets all these requirements is the orodispersible films (ODFs), which are also known as soluble films, oral disintegrating films, oral thin films or mucoadhesive films - the nomenclature changes depending on their characteristics and functionalities [20]. This innovative product can be defined as a thin film of easy dissolution and high contact surface, which allows the release of all active components into the oral cavity. Among the advantages attributed to these films are storage at room temperature, ease of obtaining, handling, and administration, not requiring water, efficient release of active components, and facilitating patient compliance to treatment. Lastly, as the oral mucosa is highly vascularized, ODF can also avoid the first-pass metabolism [21,22].

Researchers have shown that this pharmaceutical form may be the best strategy to immobilize probiotics and deliver them into specific areas such as the oral cavity. Probiotic ODF presented high microbial viability after processing, allowing a proper shelf-life, suitable disintegration time allowing the local probiotic release, and good appearance and mechanical properties $[18,19,23]$.

Those films are usually composed of macromolecules, natural or synthetic, forming a polymer matrix, plasticizers - which increase the filmogenic properties of the polymers giving greater flexibility and less fragility-and the bioactive compound of interest. The composition and proportion of such excipients can be altered according to the characteristics desired for the product [20]. The chosen polymers should be safe, have a good shelf life, should not be toxic to the probiotic, ensuring its viability and metabolic activity, as well as have a quick and efficient release $[19,24]$. Carboxymethylcellulose (CMC), hydroxypropyl methylcellulose (HPMC), and gelatin are considered good choices for films that carry probiotics $[18,19,22,23]$. However, films composed of a CMC and gelatin blend were more efficient at protecting probiotic cells during the drying process of the films, and those composed of CMC, gelatin, and starch allowed the survival of probiotics in a high concentration ( $>9 \mathrm{CFU} \cdot \mathrm{g}^{-1}$ ) for a longer period [18].

According to the characteristics of the films, these constitute carriers of bioactive substances that are ideal for patients with conditions that favor dysphagia such as the elderly, patients with motor debilities, and the immunocompromised [19,21,22]. Coincidentally, in this population, there is a high prevalence of candidiasis [19,21,22,25]. Considering the above, this study aimed to develop and characterize an ODF with the addition of the probiotic E. faecium CRL 183, evaluating its antifungal potential against C. albicans ATCC 90028 biofilms in vitro.

\section{Materials and Methods}

The probiotic strains E. faecium CRL 183 and C. albicans ATCC 90028 were obtained from the Reference Center for Lactobacilli-CERELA/CONICET (San Miguel de Tucumán, Argentina) and from American Type Culture Collection (Manassas, VA, USA), respectively. CMC was donated by Biovital (São Carlos, SP, Brazil), gelatine (260 bloom/30 mesh) was provided by Gelita (Cotia, SP, Brazil), sorbitol (Neosorb P60W) was supplied by Labonathus 
(São Paulo, SP, Brazil), alcohol-free mint flavoring was provided by Firmenich, (Cotia, SP, Brazil), and potato starch was purchased from Yoki (Pouso Alegre, MG, Brazil).

\subsection{Strains and Growth Conditions}

The strains were thawed and subcultured in specific culture media: C. albicans in Sabouraud Dextrose Agar supplemented with chloramphenicol $\left(0.05 \mathrm{~g} \cdot \mathrm{L}^{-1}\right)$ (SDAAcumedia, Lansing, MI, USA) and E. faecium in Bile Esculin Agar or M17 agar (Acumedia, Lansing MI, USA) and incubated at $37^{\circ} \mathrm{C}$ for $48 \mathrm{~h}$. C. albicans colonies, freshly cultivated as described above, were inoculated with a sterile loop in enriched broth $\left(26 \mathrm{~g} \cdot \mathrm{L}^{-1}\right.$ of BHI-Kasvi, Curitiba, Brazil; $10 \mathrm{~g} \cdot \mathrm{L}^{-1}$ of YE-Acumedia, Lansing MI, USA; $20 \mathrm{~g} \cdot \mathrm{L}^{-1}$ of TSB-Acumedia, Lansing, MI, USA; 20\% of sucrose Synth, Diadema, Brazil). This yeast suspension was standardized $\left(6 \log _{10} \mathrm{CFU} \cdot \mathrm{mL}^{-1}\right)$ by spectrophotometry reading on a Synergy H1M microplate reader (Biotek, Winooski, VT, USA). This initial concentration was based on previous study, which has shown that in our experimental design, starting the Candida albicans biofilm with an initial concentration of $6 \log _{10} \mathrm{CFU} \cdot \mathrm{mL}^{-1}$ or $8 \log _{10}$ $\mathrm{CFU} \cdot \mathrm{mL}^{-1}$ did not result in a statistically significant difference in the final population of microorganisms in the biofilms (results awaiting publication).

To prepare the probiotic inoculum, E. faecium freshly cultivated colonies were inoculated in $5 \mathrm{~mL}$ of M17 Broth (Himedia, Mumbai, India) followed by incubation at $35 \pm 2{ }^{\circ} \mathrm{C}$ for $14-16 \mathrm{~h}$. After this period, the tubes containing the inoculum were pelleted by centrifuging at $1431 \mathrm{~g}$ (80-2B Centribio-Equipar, Curitiba, Brazil) for $20 \mathrm{~min}$, washed twice with $0.9 \%(w / v) \mathrm{NaCl}$ solution (Synth, Diadema, Brazil), and resuspended in a lower volume of $0.9 \%(w / v) \mathrm{NaCl}$. The bacterial suspension obtained was standardized at $\approx 10 \log _{10} \mathrm{CFU} \cdot \mathrm{mL}^{-1}[18]$.

\subsection{Orodispersible Films Preparation}

Two formulations of ODFs-Probiotic Film (PF) and Control Film (CF)-were prepared by solvent casting as described by Heinemann et al. [18], with modifications. The procedure is outlined in Figure 1 [18]. Three dispersions of macromolecules (polymers) and plasticizer were prepared using a magnetic stirrer (Fisatom, São Paulo, SP, Brazil): $\mathrm{G}-2.00 \mathrm{~g}$ gelatin $+0.4 \mathrm{~g}$ sorbitol in $100 \mathrm{~mL}$ distilled water; PS-2.00 g potato starch $+0.4 \mathrm{~g}$ sorbitol in $100 \mathrm{~mL}$ distilled water, and CMC-1.00 g CMC $+0.2 \mathrm{~g}$ sorbitol in $100 \mathrm{~mL}$ distilled water. These dispersions were mixed in the proportion 1CMC:2PS:2G $(v / v)$ to obtain the film-forming dispersion (FD), to which $0.50 \%(w / w)$ mint powder flavoring was added. The film-forming dispersion was sterilized at $121^{\circ} \mathrm{C} / 15 \mathrm{~min}$ and then cooled to $45^{\circ} \mathrm{C}$. After that, all the steps were conducted within the laminar flow under sterile conditions. To prepare the $\mathrm{PF}, 10 \%(v / v)$ of the freshly cultured E. faecium CRL 183 inoculum was added to $\mathrm{FD}\left(45^{\circ} \mathrm{C}\right)$ under constant agitation. Two milliliters of FD were poured into $2 \times 2 \mathrm{~cm}$ holes of silicone molds to obtain films with standardized size and weight. The silicone molds were arranged in laminar flows with constant air circulation at room temperature $\left(28 \pm 2{ }^{\circ} \mathrm{C}\right)$ for $24 \mathrm{~h}$. The obtained films were carefully removed from the silicone molds and conditioned in Petri dishes at room temperature within a vacuum desiccator. The films were produced in three batches. The same procedure was used to obtain $\mathrm{CF}$, without the step of adding E. faecium CRL 183 inoculum. 


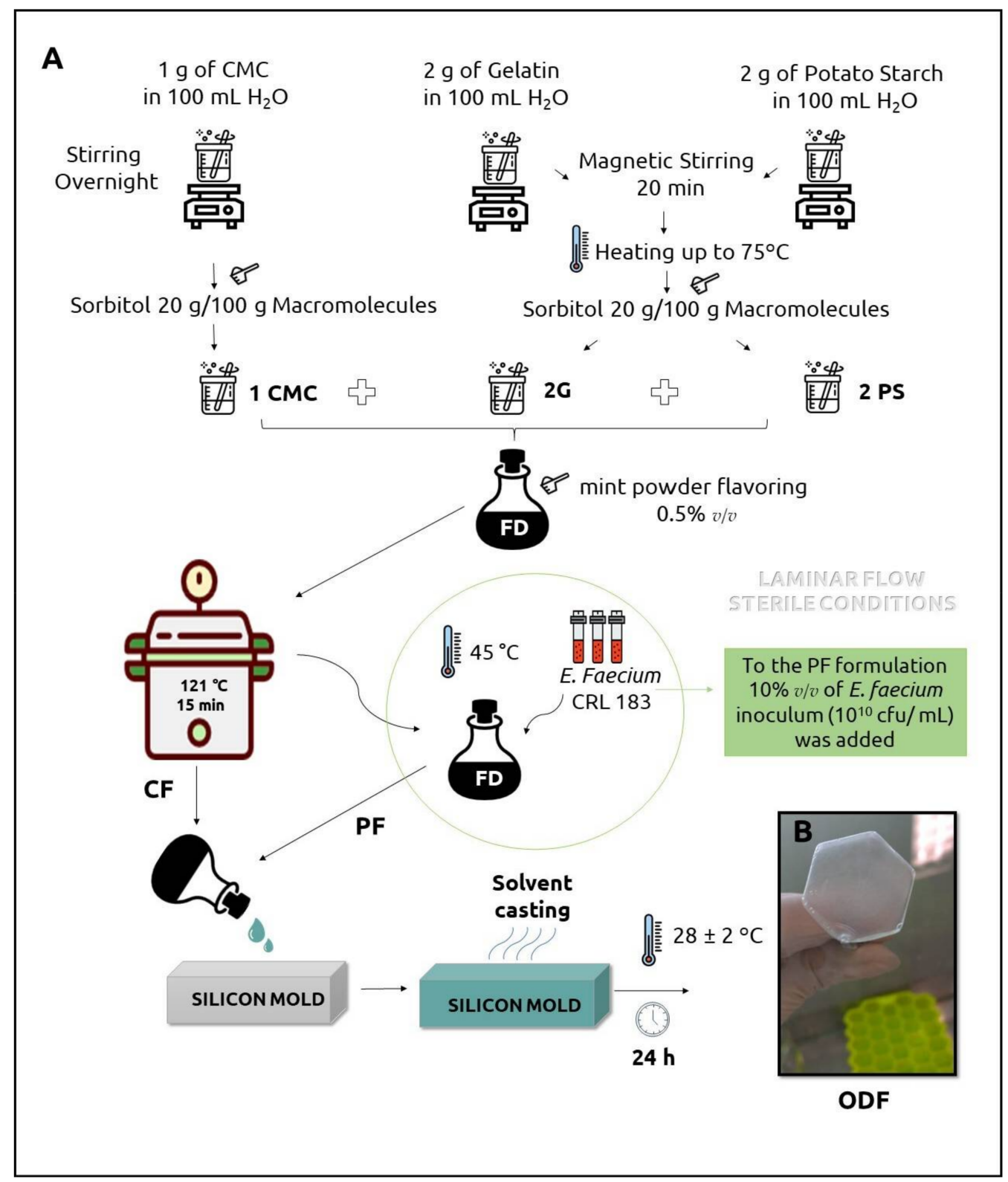

Figure 1. Orodispersible films preparation protocol (A). Orodispersible film (B).

2.3. Macroscopic Observations, Color Parameters, Thickness Analysis, pH, and Moisture Content of ODFs

The films were inspected regarding to appearance, texture, flexibility, and occurrence of bubbles and fissures. A colorimeter (Konica Minolta ${ }^{\circledR}$ Spectrophotometer CM 600d, Osaka, Kansai, Japan) was used for the assessment of color parameters (CIELAB system expressed as $L^{*}, a^{*}$ and $b^{*}$ values), in triplicate. The thickness was evaluated with a digital micrometer MDC-25SX (Mitutoyo ${ }^{\circledR}$, Kawasaki, Japan) in three random positions of each film, in sextuplicate. The $\mathrm{pH}$ of the films was determined using a digital potentiometer (Qualxtron ${ }^{\circledR}$, Model 8010, Jundiaí, Brazil), through the dissolution of a $0.1 \mathrm{~g}$ sample of the films in $20.0 \mathrm{~mL}$ of $0.9 \%(w / v) \mathrm{NaCl}$, in triplicate. The moisture content was measured in an infrared analyzer (Sartorius ${ }^{\circledR}$ MA35, Goettingen, Germany), right after the end of the drying period of the films (T0).

\subsection{Probiotic Survival in PF after Drying Process and Storage}

To evaluate the cell viability of E. faecium in the ODFs, PF samples $(0.1 \mathrm{~g})$ were solubilized in $20 \mathrm{~mL}$ of $0.9 \%(w / v) \mathrm{NaCl}$ (Synth, Diadema, Brazil) and serially diluted and 
plated (spread-plate) in M17 agar (Himedia, Mumbai, India). The results were expressed as $\log _{10} \mathrm{CFU} \cdot \mathrm{g}^{-1}$ after incubation under aerobic conditions at $37^{\circ} \mathrm{C} / 48 \mathrm{~h}$. The analyses were performed immediately after the drying process of ODF (T0) and compared to the probiotic amount added to the filmogenic solution, to evaluate the probiotic resistance to processing. To evaluate the probiotic viability over time, the analysis was performed fortnightly, during the storage period of 90 days.

\subsection{Microbiological Safety of ODFs}

The films' water activity (Aw) was measured using an Aqualab ${ }^{\circledR} \mathrm{CX} 2$ analyzer (Decagon devices, USA) after stabilization of $0.1 \mathrm{~g}$ samples at $25{ }^{\circ} \mathrm{C}$ for $30 \mathrm{~min}$. The microbiological safety of ODFs was determined monthly through the dissolution of a $0.1 \mathrm{~g}$ sample in $20.0 \mathrm{~mL}$ of sterile $\mathrm{NaCl} 0.9 \%(w / v)$. Then, this solution was serial diluted and plated on specific culture media to evaluate contamination by yeasts and molds (PDAPotato Dextrose Agar, Himedia, India, incubated at $30.0^{\circ} \mathrm{C}$, for $120 \mathrm{~h}$ ) and total coliforms (Petrifilm ${ }^{\circledR} 3 \mathrm{M}^{\circledR}$, USA, incubated at $37.0^{\circ} \mathrm{C}$, for $48 \mathrm{~h}$ ).

\subsection{In Vitro Disintegration Time}

PF or CF samples were placed at the top of a $5 \mathrm{~mL}$ Erlenmeyer flask, into which was placed a filter paper. Two hundred microliters of artificial saliva $\left(\right.$ at $\left.37^{\circ} \mathrm{C}\right)$ prepared according to Nalluri et al. [26] were placed on the films' surface. The time taken for the drop to pass through the film (T1) or to dissolve the film and form a hole in it (T2) was recorded. The tests were performed at least in triplicate.

\subsection{Liquid Uptake}

An adapted Enslin device [27,28] was used to measure the liquid uptaking ability of the ODFs. Samples of the films were weighted and placed at the bottom of the sintered glass filter of the funnel. The changes on artificial saliva volume on the graduated pipette of the device due to sample absorption were measured at 1, 2, 5, 10, 15, 20, and $30 \mathrm{~min}$. The tests were performed in triplicate, and the results were expressed as medium absorbed (\%) in relation to the initial mass of the sample as a function of time.

\subsection{Water Vapor Permeability (WVP)}

PF and CF samples were cut in circular sections and fixed at the top of glass cups with $1.1 \mathrm{~cm}$ openings. The cups were previously filled with $10 \mathrm{~mL}$ of water $(100 \%$ relative humidity gradient at $25{ }^{\circ} \mathrm{C}$ ). The set was accurately weighed and stored in a vacuum desiccator containing silica gel. Therefore, the relative humidity inside the cell was always higher than in the outside, and the water vapor transport was determined from the set mass loss.

The set weight was measured after $0,24,48,72$, and $96 \mathrm{~h}$, and the mass changes were plotted as a time function. The slope of each line was calculated by linear regression $\left(\mathrm{r}^{2}>0.99\right)$, and the water vapor transmission rate $(W V T R)$ was measured from the slope of the straight line $\left(\mathrm{g} \cdot \mathrm{h}^{-1}\right)$ by the test area $\left(\mathrm{m}^{2}\right)$. All values of WVTR were corrected for the concentration gradient effect in the stagnant air gap inside the cup as suggested by Gennadios et al. [29] Subsequently to the permeation tests, WVP $\left(\mathrm{g} \cdot \mathrm{mm} \cdot \mathrm{m}^{-2} \cdot \mathrm{h}^{-1} \cdot \mathrm{Pa}^{-1}\right)$ was calculated using Equation (1):

$$
\mathrm{WVP}=\frac{W V T R_{c} \times L}{\Delta P}
$$

where WVTRc: corrected water vapor transmission rate $\left(\mathrm{g} \cdot \mathrm{m}^{-2} \cdot \mathrm{h}^{-1}\right) ; \mathrm{L}$ : average film thickness $(\mathrm{mm}) ; \Delta P$ : water vapor pressure difference between dry atmosphere and pure water.

\subsection{Mechanical Properties of ODFs}

The mechanical properties of CF and PF were evaluated on a texture analyzer TA-XT2 (Stable Micro Systems, Haslemere, Surrey, South East, United Kingdom), using a spherical- 
ended puncture probe $(5 \mathrm{~mm})$. The films' sections were fixed on a metallic holder with a circular hole $(\mathrm{D}=10 \mathrm{~mm})$, and the probe was moved down at $1 \mathrm{~mm} \cdot \mathrm{s}^{-1}$ with constant velocity $\left(0.1 \mathrm{~mm} \cdot \mathrm{s}^{-1}\right)$. The trigger force was $0.005 \mathrm{~kg}$, and force versus displacement curves were recorded until the film rupture and used to determine the puncture strength (Ps) and elongation at break ( $\left.\mathrm{E}_{\mathrm{b}} \%\right)$ parameters, according to the following Equations (2) and (3) [30].

$$
\text { Ps }=\frac{F}{A}
$$

where $F(\mathrm{~N})$ : force required to rupture the film; $A\left(\mathrm{~m}^{2}\right)$ : sectional area of the film $(A=2 r \cdot \mathrm{h}$, where $r$ is the hole radius and $h$ is the film thickness).

$$
\mathrm{E}_{\mathrm{b}} \%=\frac{\sqrt{r^{2}+d^{2}}-r}{r} \times 100
$$

where $r(\mathrm{~mm})$ : radius of the exposed film on the orifice plate and $d$ is the displacement.

\subsection{Mucoadhesive Force}

The mucoadhesive strength of PF and CF was evaluated by measuring the force required to detach the ODFs from a mucin disc using a TA-XT2 Texture Analyzer (Stable Micro Systems) [31]. Mucin discs were hydrated with artificial saliva (25 $\mu \mathrm{L})$ and placed on a support for mucoadhesion test. ODFs were attached with double-sided tape to the analytical probe $(10 \mathrm{~mm})$, which was then lowered $\left(10 \mathrm{~mm} \cdot \mathrm{min}^{-1}\right)$ until the mucin disc was in contact with the surface of the films. The complex mucin disc films were kept in contact for $60 \mathrm{~s}$, and then, the probe was moved up at a constant speed $\left(20 \mathrm{~mm} \cdot \mathrm{min}^{-1}\right)$. The maximum force needed to detach the films from mucin discs, mucoadhesive force (FMA), was recorded.

\subsection{Evaluation of the Probiotic Film (PF) Anti-Candida albicans Activity}

To evaluate whether PF would prevent C. albicans biofilm formation and maturation, biofilm assays were carried out following the methods described by Fontana et al. [32] and Zago et al. [33], with modifications. The assays were conducted on 6-well microplates with each well containing $2 \mathrm{~mL}$ of standard yeast inoculum (prepared as described in strains and growth conditions) plus $2 \mathrm{~mL}$ of enriched broth, i.e., $4 \mathrm{~mL}$ per well. In the test group, a sample of $0.1 \mathrm{~g}$ of PF (containing approximately $9 \log _{10}$ CFU.g ${ }^{-1}$ E. faecium) was added to each well immediately afterwards. To the control group, $0.1 \mathrm{~g}$ of CF was added to the wells immediately afterwards. The microplates were incubated at $35 \pm 2{ }^{\circ} \mathrm{C}$ for $24 \mathrm{~h}$ to evaluate the action of the probiotic film in C. albicans biofilm adhesion and formation and for $48 \mathrm{~h}$ to evaluate it in the biofilm maturation. After that, the supernatant of the biofilms was carefully removed, and its $\mathrm{pH}$ was assessed with $\mathrm{pH}$-fix (Neumann-Neander, Düren, Germany), and the adhered biofilms were scraped off the wells and resuspended vigorously in $4 \mathrm{~mL}$ of enriched broth with a sterile pipette tip for $30 \mathrm{~s}$. Serial decimal dilutions of those suspensions were made using as diluent the culture medium itself. Microorganisms were quantified by plating in SDA supplemented with chloramphenicol. The plates were incubated for $24 \mathrm{~h}$ at $35 \pm 2{ }^{\circ} \mathrm{C}$, and the number of fungal cells present in the biofilms was expressed in CFU. $\mathrm{mL}^{-1}$. The experiments were performed in triplicate and repeated in three independent assays.

The decimal reduction (DR) of Candida albicans cell viability in the presence of PF was determined by Equation (4) [34]:

$$
\mathrm{DR}=\log _{10}\left(\mathrm{Ca}_{\mathrm{CF}}\right)-\log _{10}(\mathrm{CaPF})
$$

where $\mathrm{Ca}_{\mathrm{CF}}$ : $\mathrm{CFU} \cdot \mathrm{mL}^{-1}$ values of $C$. albicans present in the biofilms stimulated with control films (CF); CapF: CFU. $\mathrm{mL}^{-1}$ values of C. albicans present in the biofilms stimulated with probiotic films (PF). 
Then, the percentual reduction (PR) of fungal population after 24 or $48 \mathrm{~h}$ was calculated with Equation (5) [34]:

$$
\mathrm{PR}=\left(1-10^{-\mathrm{DR}}\right) \times 100
$$

where DR is the decimal reduction obtained by Equation (4).

\subsection{Field Emission Gun Scanning Electron Microscopy (FEG-SEM)}

PF and CF surface and transversal section morphology as well as the interactions between C. albicans and PF or CF in the early and mature biofilms were assessed by FEGSEM (JEOL JSM-7500F, Tokyo, Japan). Biofilms were formed as described above in a sterile coverslip placed at the bottom of 6-well microtiter plates. After the incubation period (24 h or $48 \mathrm{~h}$ ), the biofilms' supernatants were gently removed, and the coverslip was washed with PBS. The biofilms were fixed with a $2.5 \%$ glutaraldehyde solution (Merck, Darmstadt, Germany) and then dehydrated with an ethanol series (30\%, 50\%, 70\%, 85\%, and $95 \%$ ethanol solution for 15 min each; two washes with $100 \%$ ethanol for $15 \mathrm{~min}$ ). The samples were dried at $37^{\circ} \mathrm{C}$ and kept in a vacuum desiccator until the analysis day. For cross-section observations, PF and CF samples were cryofractured by immersion in liquid nitrogen. PF, CF, or the coverslips containing adhered biofilms were attached to the slab surfaces with double-sided adhesive tape and then coated with a layer of carbon and observed through FEG- SEM (JEOL JSM-7500F, Tokyo, Japan).

\subsection{Statistical Analysis}

To verify the statistical significance, the results were submitted to one-way ANOVA followed by Tukey's multiple comparisons test or Student's $t$-test (for parametric data) and the Mann-Whitney test (for non-parametric data). It was performed using GraphPad Prism version 7.00 for Windows (GraphPad Software, La Jolla, CA, USA) with a minimum significance level of $5 \%(p \leq 0.05)$.

\section{Results}

3.1. Macroscopic Observations, Color Parameters, Thickness, $p H$, Moisture, and Water Activity (Aw) of ODFs

The physicochemical characteristics of ODFs are listed in Table 1. Both CF and PF were macroscopically homogeneous, and without bubbles or fissures (Figure 1B). The incorporation of probiotic increased the thickness, moisture, Aw, and the $b^{*}$ color parameter coordinate (from blue to yellow) $(p<0.0001)$ of ODF. The $\mathrm{pH}$ of PF was slightly lower than CF $(p<0.03)$.

Table 1. Physicochemical characterization of ODFs.

\begin{tabular}{cccccc}
\hline & Thickness (mm) & Color $\left(\mathbf{L}^{*}, \mathbf{a}^{*}, \mathbf{b}^{*}\right)$ & Moisture (\%) & pH & Aw \\
\hline CF & $0.080 \pm 0.001^{A}$ & $\begin{array}{c}\mathrm{L}^{*}=33.53 \pm 1.67 \\
\mathrm{a}^{*}=-0.24 \pm 0.13 \\
\mathrm{~b}^{*}=-0.49 \pm 0.26^{\mathrm{a}}\end{array}$ & $12.57 \pm 0.14^{\mathrm{A}}$ & $6.94 \pm 0.003^{\mathrm{A}}$ & $0.378 \pm 0.04^{\mathrm{A}}$ \\
\hline PF & $0.100 \pm 0.001^{\mathrm{B}}$ & $\begin{array}{c}\mathrm{L}^{*}=34.28 \pm 1.12 \\
\mathrm{a}^{*}=-0.22 \pm 0.04 \\
\mathrm{~b}^{*}=+0.80 \pm 0.16^{\mathrm{b}}\end{array}$ & $15.41 \pm 0.26^{\mathrm{B}}$ & $6.91 \pm 0.005^{\mathrm{B}}$ & $0.404^{\mathrm{N}} \pm 0.05^{\mathrm{B}}$ \\
\hline
\end{tabular}

Means \pm SD. Means in the same column followed by different capital letters (A or B) are significantly different by $t$-test ( $p<0.0001$ for thickness, color, moisture, and Aw; $p<0.003$ for $\mathrm{pH}$ ). Means in the same column followed by different lowercase letters (a or b) are significantly different by Mann-Whitney test $(p<0.0001)$.

\subsection{Probiotic Survival and Microbiological Safety}

We observed a reduction in the E. faecium CRL183 viability after the drying process was applied to the film production (Figure 2A). However, probiotic cell viability was $9.19 \pm 0.58 \log _{10} \mathrm{CFU} \cdot \mathrm{g}^{-1}$ right after the drying process and remained stable (>9 $\log _{10} \mathrm{CFU} \cdot \mathrm{g}^{-1}$ ) up to 90 days after the films were formulated (Figure 2B). The ODFs were considered safe, since the population of yeasts and molds and coliforms were less than $1 \log _{10} \mathrm{CFU} \cdot \mathrm{g}^{-1}$. 
A

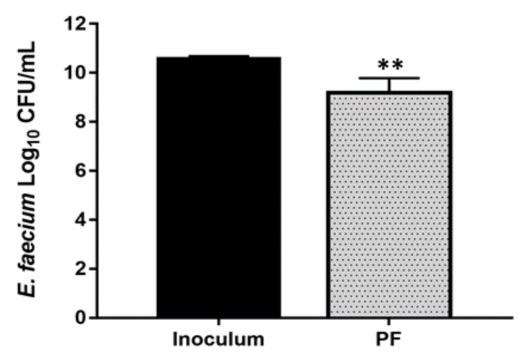

B

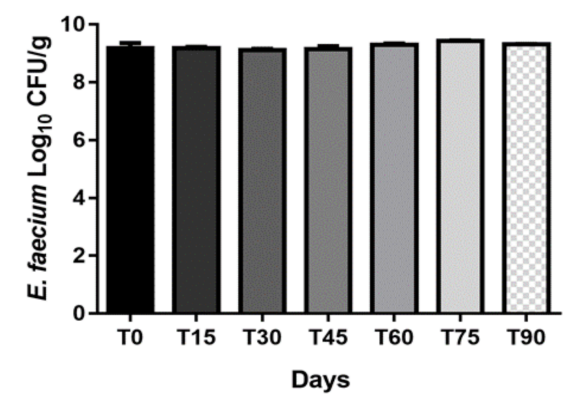

Figure 2. Probiotic resistance. (A) Probiotic viability in the inoculum and in PF (Probiotic Film) after drying, according to $t$-test $\left({ }^{* *} p=0.002\right)$. (B) Probiotic viability during storage, according to ANOVA followed by Tukey's test.

\subsection{In Vitro Disintegration Time and Liquid Uptake}

There was no difference between the disintegration time for PF (T1: $1.35 \mathrm{~min}$; T2: $6.43 \mathrm{~min}$ ) and CF (T1:1.28 min; T2: $5.50 \mathrm{~min}$ ) (Figure 3A). Either PF and CF presented a high and fast ability of artificial saliva uptake (i.e., PF: 297\%; CF: 315\%) after only $1 \mathrm{~min}$, reaching approximately $600 \%$ after 30 min of analysis $(p>0.05)$ (Figure 3B). The mass loss was the same for both ODFs $(p>0.05)$ (Figure 3C).
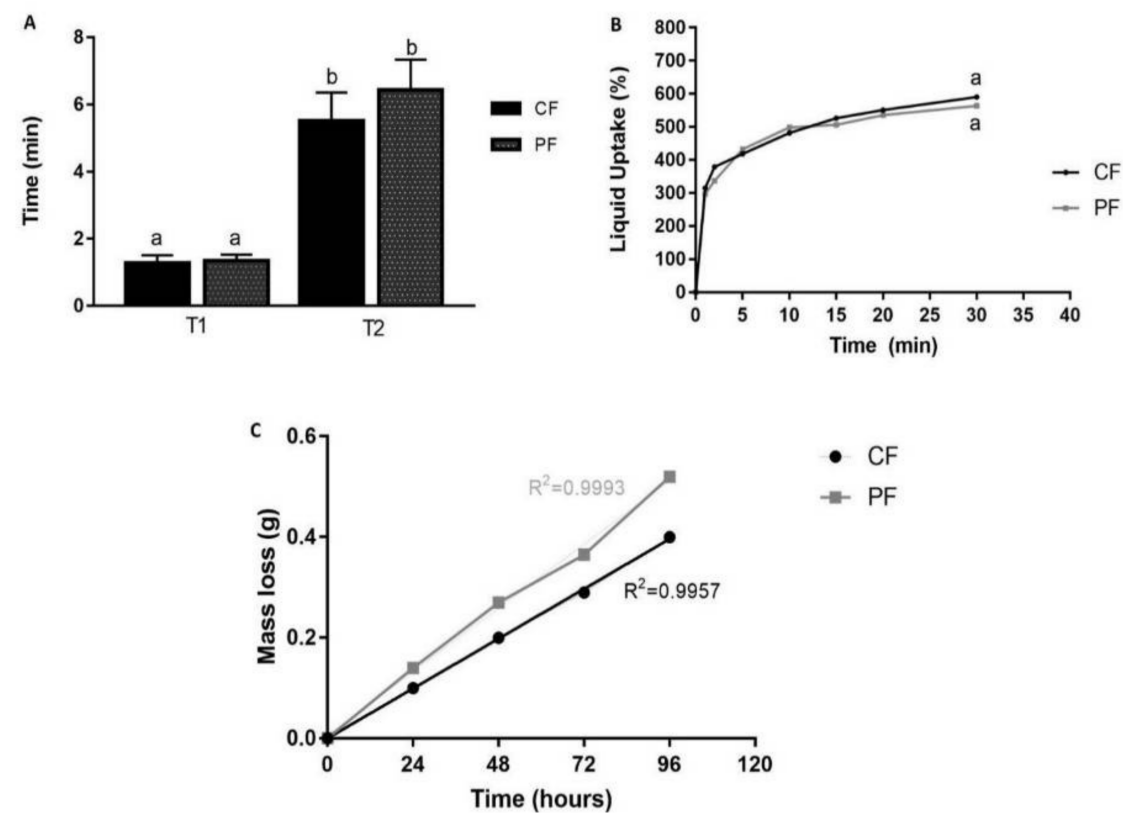

Figure 3. Disintegration time of ODFs; (A) T1: time in which artificial saliva cross the films; T2: time to complete disintegration (appearance of a hole). (B) CF and PF uptake of artificial saliva over time. (C) Mass loss in water vapor permeability test over time. Same lowercase letters show statistical equality according to $t$-test.

\subsection{Mechanical Properties, Water Vapor Permeability (WVP), and Mucoadhesive Force}

The probiotic incorporation into the matrix enhanced significantly $(p=0.01)$ WVP and elongation at break values, which can be explained by the greater thickness in these films. The CF and PF were considerably resistant, and the probiotic incorporation did not alter the puncture strength (Ps) and mucoadhesive (FMA) force of the films (Table 2). 
Table 2. Mechanical properties, water vapor permeability (WVP), and mucoadhesive force of PF and CF.

\begin{tabular}{ccccc}
\hline Films & WVP $\left(\times \mathbf{1 0}^{-\mathbf{5}} \mathbf{g ~ m m ~ m}^{-\mathbf{2}} \mathbf{h ~}^{-\mathbf{1}} \mathbf{P a}^{-\mathbf{1}}\right)$ & Ps $\mathbf{~ M P a})$ & Eb (\%) & FMA (n) \\
\hline CF & $1.27 \pm 0.1^{\mathrm{A}}$ & $25.61 \pm 2.2^{\mathrm{A}}$ & $4.13 \pm 0.87^{\mathrm{A}}$ & $0.060 \pm 0.01^{\mathrm{A}}$ \\
$\mathrm{PF}$ & $1.93 \pm 0.2^{\mathrm{B}}$ & $25.92 \pm 2.9^{\mathrm{A}}$ & $9.40 \pm 0.95^{\mathrm{B}}$ & $0.064 \pm 0.011^{\mathrm{A}}$ \\
\hline
\end{tabular}

Results presented as mean \pm SD. $(n=3)$. Means in the same column followed by different capital letters (A or B) are significantly different by $t$-test $(p=0.03)$. WVP: Water vapor permeability; Ps: Puncture strength; Eb: Elongation at break; FMA: Mucoadhesive Force.

\subsection{Evaluation of the Probiotic Film (PF) Anti-Candida albicans Activity}

The probiotic was efficiently released from the polymeric film, and it impaired in $68.9 \%\left(\mathrm{DR}=0.52 \log _{10}\right)$ of the C. albicans early biofilm and in $91.24 \%\left(\mathrm{DR}=1.15 \log _{10}\right)$ of the the fungal mature biofilm compared to the group stimulated with CF (Figure 4).

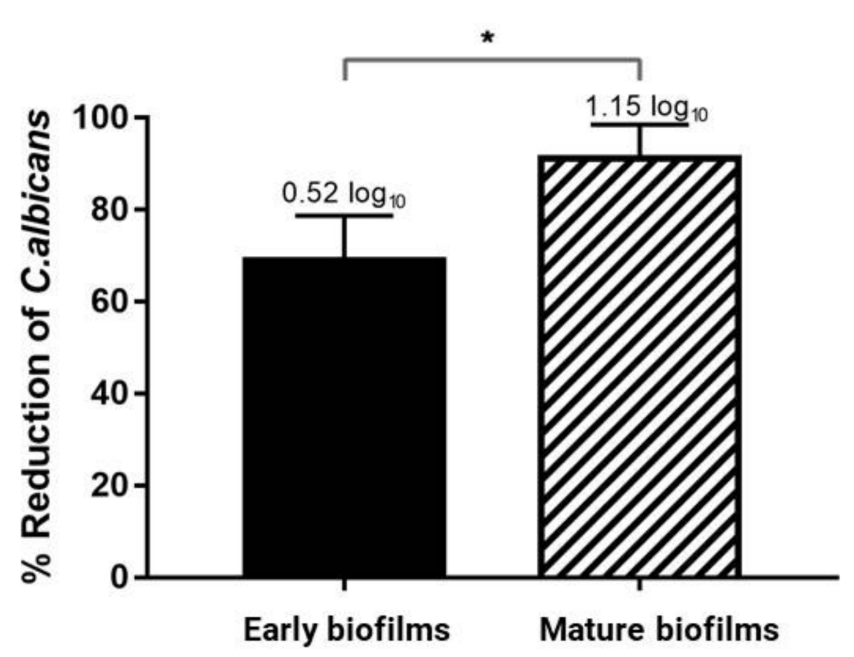

Figure 4. Percentual reduction of $C$. albicans early and mature biofilms biofilm in the presence of PF (Probiotic Film). Each column represents the mean of three independent experiments, each performed in triplicate $(n=9)$, the bars represent the standard deviation. Numbers above columns represent the decimal reduction (DR) The asterisk indicates statistically significant difference $\left({ }^{*} p=0.03\right)$ between early and mature biofilms, according to $t$-test.

\subsection{Field Emission Gun Scanning Electron Microscopy (FEG-SEM)}

The photomicrographs shown in Figure 5 reveal that both CF (Figure 5A) and PF (Figure 5D) present the whole surface without fissures in their structure. Both films' surfaces were very rough, and the cross-sections SEM images confirmed that PF was thicker than CF.

The photomicrographs of $C$. albicans biofilms stimulated with PF (Figure 5E,F) show free probiotic cells, reassuring the effective release of the probiotic from the polymeric matrix. The SEM images also confirmed the results discussed in section Evaluation of the Probiotic film (PF) anti-Candida activity, demonstrating that there was an alteration in the morphology of $C$. albicans, suggesting cell injury in the presence of PF (Figure 5E,F) if compared with the CF group (Figure 5B,C). Furthermore, the biofilms stimulated with $\mathrm{CF}$ presented C. albicans cells surrounded by a very thick matrix, which occurs in a lesser amount in the biofilms stimulated with PF (Figure 5E,F). In the mature biofilms (Figure 5C,F), it is also possible to notice that yeast cells presented a wrinkled morphology (indicated by the arrow) only when stimulated with PF (Figure 5F), which may indicate that E. faecium promotes yeast cell injury, preventing yeast growth and even leading to its death. Future studies have to be conducted to evaluate changes in the expression levels of genes encoding key role proteins for C. albicans adhesion during biofilm development (ALS1 and ALS3). 


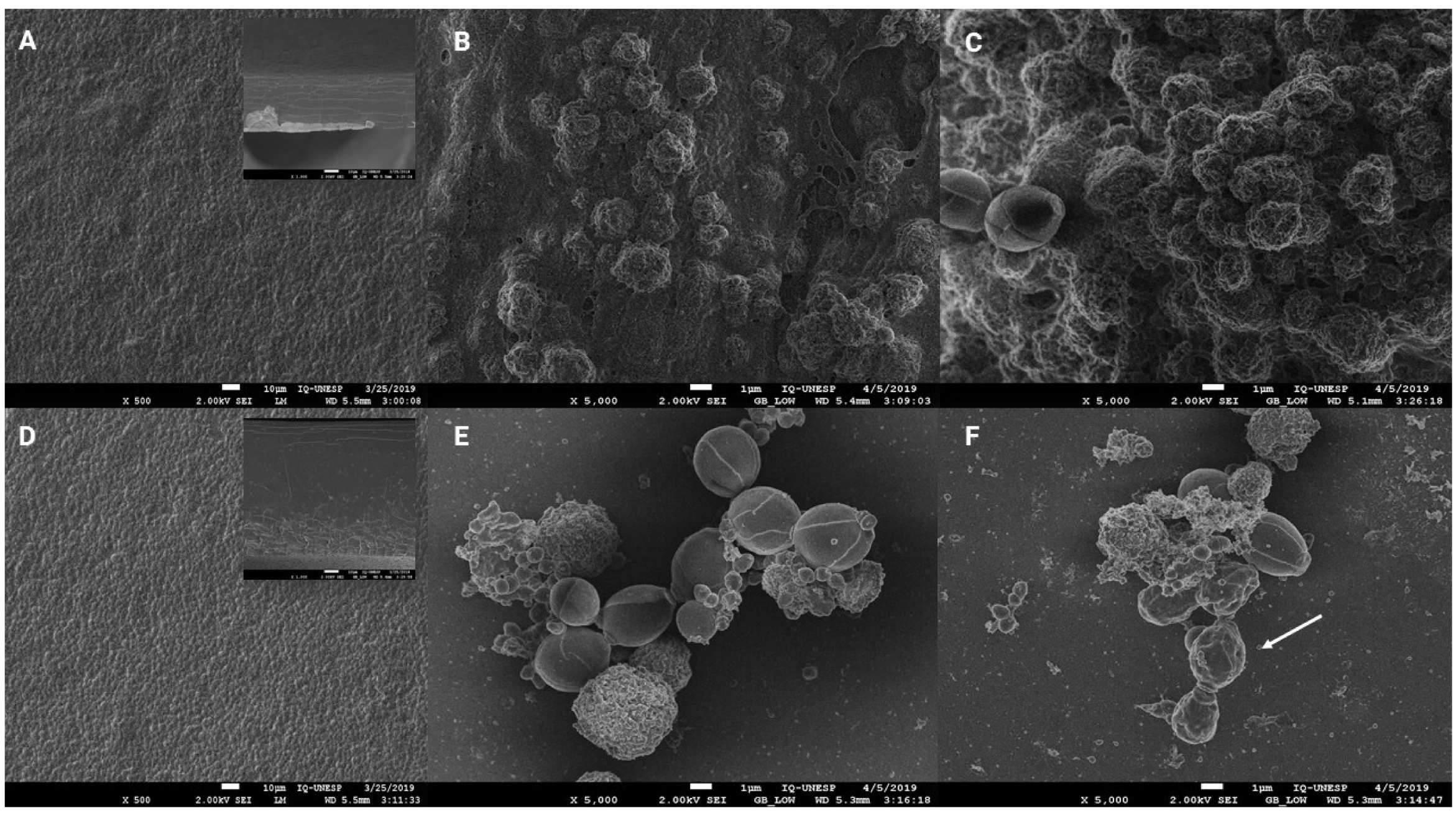

Figure 5. FEG-SEM images. Surface of the ODFs: (A) CF 500 $\times$ and (D) PF 500 $\times$. The respective cross-sections of each ODF were taken at $1000 \times$ and are embedded into the right-hand corner of (A,D). Biofilms at 5000 $\times$ magnification: C. albicans + CF early (B); C. albicans + CF mature (C); C. albicans + PF early (E); C. albicans + PF mature (F). The arrow indicates the wrinkled morphology of $C$. albicans after $48 \mathrm{~h}$ in the presence of PF. 


\section{Discussion}

The E. faecium CRL 183 strain has beneficial effects in in vitro and in vivo models $[17,35-38]$. In this study, we demonstrated that the same strain reduces the biofilm formation of Candida albicans when carried in ODFs, without impairing the characteristics of this pharmaceutical form.

Regarding the physicochemical characteristics of ODFs, PF thickness, moisture, and Aw were expected to be higher once there was an incorporation of a great amount $\left(10^{10} \mathrm{CFU} \cdot \mathrm{mL}^{-1}\right)$ of probiotic into the polymeric matrix. The residual moisture content in CF was remarkably similar to the results obtained by Heinemann et al. [24], in a formulation also composed by CMC, gelatin, and starch. However, the optimal residual moisture content to maximize the stability of the probiotic varies with the composition of the medium in which it was dehydrated, the storage atmosphere, and the strain, and therefore, it must be determined in each situation [23].

Water activity is the main intrinsic factor related to its physicochemical and microbiological deterioration. Aw values lower than 0.6, similar to those that found in this study, are unfavorable to the growth of contaminating and pathogenic microorganisms while favoring the cellular viability of microorganisms intentionally incorporated into products $[17,39]$. This is in accordance with the microbiological safety results obtained in this study, as the PF and CF did not show contamination by yeasts and molds or total coliforms in all analyzed times. The ODFs were slightly opaque, and the increase in "b" color parameter of $\mathrm{PF}$ was expected once the probiotics inoculum had a cream color, promoting this increase $(p<0.0001)$ in the yellow parameter compared to CF. The difference between the $\mathrm{pH}(p<0.003)$ between formulations can be explained by the production of lactic acid by E. faecium [40], which decreases the PF $\mathrm{pH}$.

The loss in E. faecium cell viability during the processing of the films developed in the present study was $1.24 \pm 0.15 \log _{10} \mathrm{CFU} \cdot \mathrm{g}^{-1}$ (Figure 2A). The viability reduction is expected, since the inoculum was diluted in the polymeric matrix and was exposed to mechanical stress and oxygen during the production of ODFs. Other studies have found a similar reduction in the viability of Lactobacillus acidophilus and Bifidobacterium animalis subsp. lactis loaded in films composed of CMC, gelatin, and starch [18] or the strain Bifidobacterium breve NCIMB 8807 incorporated into a polymeric matrix composed of hydroxypropyl methylcellulose [23].

Concerning the viability during storage (90 days), the population of E. faecium in PF was high $\left(<9 \log _{10} \mathrm{CFU} \cdot \mathrm{g}^{-1}\right)$ and constant. Heinemann et al. [18] also verified that Bifidobacterium animalis subsp. lactis and Lactobacillus acidophilus loaded in ODF (CMCcellulose/gelatin/starch) remained viable for 2 months at room temperature. However, after 90 days, the microbial counts were heterogeneous, mainly for ODFs under vacuum package [18]. Highlighting that in a previous study, Witzler et al. [17] failed to incorporate E. faecium CRL 183 microencapsulated in lozanges, given that its viability decreased from $8.73 \log _{10} \mathrm{CFU} \cdot \mathrm{g}^{-1}$ to $5.53 \log _{10} \mathrm{CFU} \cdot \mathrm{g}^{-1}$ shortly after its incorporation, reaching only 1.86 $\log _{10}$ CFU.g $g^{-1}$ after 28 days of storage. Therefore, the ODF can be a simple and inexpensive way of protection and delivery of E. faecium CRL 183, since they are composed by simple and cheap polymers, and the drying process can be performed at room temperature $[19,23]$.

When in contact with biological fluids, ODFs prepared with water-soluble polymers absorb water, leading to volume expansion (swelling) and disintegration. The speed of this process is closely related to the concentration of polymers (the higher, the slower the rate of disintegration) and the interaction of the bioactive compound with the polymer. In this test, it was possible to observe that the films in contact with the artificial saliva quickly swell and form a hydrogel, allowing part of the volume of the saliva to pass through the film (T1), and later, there is the appearance of an orifice (T2) in the films, characterizing the complete disintegration, as described by Garsuch and Breitkreutz [41].

The literature and pharmacopeias do not establish an official threshold for the endpoint of in vitro disintegration tests, stating only that ODF should disperse rapidly $[19,21,41]$. 
The T1 observed (PF: $1.35 \mathrm{~min}$ and CF $1.28 \mathrm{~min}$ ) was in accordance with the European Pharmacopeia (2013) [42] orientation for the disintegration threshold for orodispersible tablets (ODTs), which should be within three minutes (180 s). Furthermore, there was an instant swell of the films resulting in a hydrogel which, with the mouth movements, would have been disintegrated [43]. Considering the complete disintegration and appearance of a hole (T2), Heinemann et al. [24] suggested the average time of four minutes as the ideal for the in vitro disintegration of ODF, since this time allows the gradual release of bioactive compounds incorporated into the polymer matrix, without causing fatigue to the consumer. In this same study, the mean in vitro disintegration time was (6.50 $\pm 0.67 \mathrm{~min})$, which is very similar to the T2 obtained in our study (PF: $6.43 \mathrm{~min}$ and CF $5.5 \mathrm{~min}$ ), for an ODF also composed of $\mathrm{CMC}$, gelatin, and starch [24]. Our results are also in the same time interval of other formulations composed by CMC [24] or gelatin and hydrolyzed collagen [22].

There is a correlation between liquid uptake and the effective release of active pharmaceutical ingredient (API) or bioactive compounds from drug delivery systems [44]. The liquid uptake can also predict the enzymatic degradation of the polymeric matrix and consequently the release of API [27]. CP and PF showed high saliva absorption, and the incorporation of the probiotic did not significantly alter the liquid uptake ability of the films. This was expected once the films were composed of high hydrophilic compounds such as CMC and starch [24,27]. CMC contains hydroxy and carboxyl groups, for which $\mathrm{pH}$ values around 7.0 promote the ionization and consequent repulsion of chains with network dilation, favoring the water entrance. Furthermore, the entanglement level of the structures can also play a role in the high liquid uptake presented by CF and PF. The low concentration of polymers in PF and CF composition promotes a looser network that favors water molecule diffusion, compared to stronger structures [28] (Figure 3B). The higher polymeric mass promotes more water absorption $[27,28]$. Although the addition of new components to polymeric films generally causes the increase in the diffusional path and the barrier properties [45], it was observed that the probiotics incorporation caused the rise of the vapor permeability's rates. This behavior may be related to the higher moisture content, giving the films a greater affinity for water.

The resistance to cracking during processing, transport, and storage is an important characteristic of polymeric films, and it is determined by its mechanical properties [27]. Elongation at break (Eb\%) determines the maximum deformation that a material can undergo before it cracks and, for oral applications, films must be flexible enough to comfortably follow the movement of the mouth [46]. PF was twice as flexible as CF, which can be explained by the residual moisture difference between the two polymeric films; water can act as a plasticizer, intercalating with the polymer chains and therefore enhancing flexibility [21]. Furthermore, loaded films can promote a rearrangement in the polymeric microstructure in a more flexible way [30].

Although mucoadhesive systems can promote a higher residence time in the biological target site, increasing the bioavailability of the active compound [47], the mucoadhesive force of PF and CF was surprisingly low. It is known that mucoadhesive properties can vary with environment-related factors such as $\mathrm{pH}$, contact time, swelling, and physiological characteristics [47]. In this specific case, the fast swellings of the films followed by their disintegration are mechanisms that oppose the establishment of mucoadhesive interactions.

It was determined by our research group that E. faecium CRL 183 free cells were able to impair C. albicans biofilm formation and maturation in up to $99.9 \%$ and $99.43 \%$, respectively, without losing its own viability (data not shown). Among the inhibitory mechanisms exerted by Enterococcus spp. on Candida spp. Biofilms, the following stand out: competition for nutrients and space, culture media acidification, and secretion of anti-Candida peptides, proteases, and other metabolites [9,14-16].

Graham et al. [16] described that the enterocin EntV, which is encoded by a gene present in all strains of $E$. faecalis sequenced to date, were able to inhibit several virulence factors of $C$. albicans in addition to decreasing the fungal load and increasing the immune response in a murine model of oral candidiasis. However, on our previous study, it was 
verified that metabolites produced by E. faecium CRL 183 did not exert a fundamental role in its anti-Candida activity, and the acidification of the environment and physical competition seems to be the mechanisms by which this antagonism occurs (results awaiting publication). Those anti-Candida strategies are also used for several other probiotic strains [6,48-50].

It is known that the optimal $\mathrm{pH}$ to $C$. albicans spp. virulence expression is neutral to alkaline [51]. The $\mathrm{pH}$ of biofilms (early and mature) stimulated with PF were around 5.0 and with CF were around 7.0, which indicates the production of acid by the probiotic, which was expected since E. faecium CRL 183 is a lactic acid bacterium (LAB) [11]. This acidification in the environment could have promoted the yeast cell energy exhaustion, inhibiting its multiplication and leading to cell death [5]. Both competition for nutrients and space and yeast cell exhaustion are possible mechanisms related to the reduction of $C$. albicans biofilms when exposed to PF.

The lesser percentage reduction in the stimuli with PF compared to the stimuli with free cells of the previous study (data not shown) was expected once the probiotic must be firstly released from the polymeric matrix in which it is entrapped in a latent phase without metabolic activity [23]. However, in the context of candidiasis prevention, the results obtained in the present study are very promising, since the C. albicans viability reductions were similar to results obtained by other studies with different probiotic strains as free cells [48-50]. Probiotic free cells applied into the oral cavity could be removed by the salivary flow within seconds, and therefore, the probiotic would not be able to establish itself in this environment. Moreover, it could present unpleasant sensory properties. Therefore, the present study demonstrates that the ODF containing E. faecium CRL 183 may be a more advantageous prevention strategy, since it permits local probiotic release in an adequate amount of time with a good ability to impair C. albicans biofilm formation and maturation.

\section{Conclusions}

In conclusion, the PF developed is a promising strategy to prevent oral candidiasis, since it permits the E. faecium CRL 183 local delivery which, in its turn, was able to reduce C. albicans biofilm formation (68\%) and maturation (91\%) in vitro. Furthermore, the ODF made of cheap polymers and with a remarkably simple technique was able to maintain high and long-lasting probiotic viability ( $9 \log _{10} \mathrm{CFU} \cdot \mathrm{g}^{-1}$ up to 90 days). In addition, it was a suitable way to protect this microorganism during storage, as shown by its good mechanical and barrier properties. Nevertheless, the film was flexible and presented great liquid uptake ability, efficiently releasing the probiotic from a polymeric matrix within a few minutes. These results point the way for future preclinical and clinical studies, which may confirm the anti-Candida albicans potential of this probiotic film.

Author Contributions: Conceptualization, M.P.T., M.C., C.R.F. and D.C.U.C.; Data curation, V.B.L., A.B.M. and S.R.d.A.; Formal analysis, M.P.T., M.C. and D.C.U.C.; Funding acquisition, M.C., C.R.F. and D.C.U.C.; Investigation, V.B.L., A.B.M. and S.R.d.A.; Methodology, V.B.L., A.B.M., S.R.d.A. and D.C.U.C.; Project administration, M.P.T., M.C., C.R.F. and D.C.U.C.; Resources, D.C.U.C.; Supervision, M.P.T., M.C., C.R.F. and D.C.U.C.; Validation, V.B.L., A.B.M., S.R.d.A., M.P.T., M.C., C.R.F. and D.C.U.C.; Writing—original draft, V.B.L., A.B.M. and S.R.d.A.; Writing-review and editing, M.P.T., M.C., C.R.F. and D.C.U.C. All authors have read and agreed to the published version of the manuscript.

Funding: This research was funded by the Coordenação de Aperfeiçoamento de Pessoal de Nível Superior-Brasil (CAPES) -Finance Code 001, by CNPq (Conselho Nacional de Desenvolvimento Científico e Tecnológico) with master scholarship of Virginia Barreto Lordello and by Fundação de Amparo à Pesquisa do Estado de São Paulo-FAPESP (Grants \# 2018/23015-7 and 2018/09088-1).

Institutional Review Board Statement: Not applicable.

Informed Consent Statement: Not applicable.

Data Availability Statement: Not applicable. 
Acknowledgments: We would like to thank Marcelo Orlandi and the technician Diego LuizTita from the MEV-FEG laboratory at IQ-UNESP, who collaborated with the SEM analysis. We would also like to thank the companies, Gelita, Labonathus, Biovital, Firmenich, and TIC GUMS, who collaborated with the supply of materials for the research.

Conflicts of Interest: The authors declare no conflict of interest.

\section{References}

1. FAO (Food and Agricultural Organization of the United Nations); World Health Organization. Joint FAO/WHO Working Group Report on Drafting Guidelines for the Evaluation of Probiotics in Food. Food and Agricultural Organization of the United Nations. 2002. Available online: ftp:/ /ftp.fao.org/es/n/food/wgreport2.pdf (accessed on 19 March 2021).

2. Hill, C.; Guarner, F.; Reid, G.; Gibson, G.R.; Merenstein, D.J.; Pot, B.; Morelli, L.; Canani, R.B.; Flint, H.J.; Salminen, S.; et al. The International Scientific Association for Probiotics and Prebiotics consensus statement on the scope and appropriate use of the term probiotic. Nat. Rev. Gastroenterol. Hepatol. 2014, 11, 506-514. [CrossRef]

3. Ishikawa, K.H.; Mayer, M.; Miyazima, T.Y.; Matsubara, V.H.; Silva, E.G.; Paula, C.R.; Campos, T.T.; Nakamae, A.E.M. A Multispecies Probiotic Reduces Oral Candida Colonization in Denture Wearers. J. Prosthodont. 2015, 24, 194-199. [CrossRef] [PubMed]

4. Matsubara, V.H.; Bandara, H.; Mayer, M.; Samaranayake, L.P. Probiotics as Antifungals in Mucosal Candidiasis. Clin. Infect. Dis. 2016, 62, 1143-1153. [CrossRef] [PubMed]

5. Jørgensen, M.R.; Kragelund, C.; Jensen, P.Ø.; Keller, M.K.; Twetman, S. Probiotic Lactobacillus reuteri has antifungal effects on oral Candida species in vitro. J. Oral Microbiol. 2017, 9, 1274582. [CrossRef] [PubMed]

6. Mailänder-Sanchez, D.; Braunsdorf, C.; Grumaz, C.; Muller, C.; Lorenz, S.; Stevens, P.; Wagener, J.; Hebecker, B.; Hube, B.; Bracher, F.; et al. Antifungal defense of probiotic Lactobacillus rhamnosus GG is mediated by blocking adhesion and nutrient depletion. PLoS ONE 2017, 12, e0184438. [CrossRef]

7. Pujia, A.; Costacurta, M.; Fortunato, L.; Merra, G.; Cascapera, S.; Calvani, M.; Gratteri, S. The probiotics in dentistry: A narrative review. Eur. Rev. Med. Pharmacol. Sci. 2017, 21, 1405-1412. [PubMed]

8. Fanning, S.; Mitchell, A.P. Fungal Biofilms. PLoS Pathog. 2012, 8, e1002585. [CrossRef]

9. Shekh, R.M.; Roy, U. Biochemical characterization of an anti-Candida factor produced by Enterococcus faecalis. BMC Microbiol. 2012, 12, 132. [CrossRef]

10. Saavedra, L. Homemade traditional cheeses for the isolation of probiotic Enterococcus faecium strains. Int. J. Food Microbiol. 2003, 88, 241-245. [CrossRef]

11. Hanchi, H.; Mottawea, W.; Sebei, K.; Hammami, R. The Genus Enterococcus: Between Probiotic Potential and Safety ConcernsAn Update. Front. Microbiol. 2018, 9, 1791. [CrossRef]

12. Mason, K.L.; Downward, J.R.; Mason, K.D.; Falkowski, N.R.; Eaton, K.A.; Kao, J.Y.; Young, V.B.; Huffnagle, G.B. Candida albicans and Bacterial Microbiota Interactions in the Cecum during Recolonization following Broad-Spectrum Antibiotic Therapy. Infect. Immun. 2012, 80, 3371-3380. [CrossRef]

13. Mason, K.L.; Downward, J.R.E.; Falkowski, N.R.; Young, V.B.; Kao, J.Y.; Huffnagle, G.B. Interplay between the Gastric Bacterial Microbiota and Candida albicans during Postantibiotic Recolonization and Gastritis. Infect. Immun. 2011, 80, 150-158. [CrossRef]

14. Cruz, M.R.; Graham, C.; Gagliano, B.C.; Lorenz, M.C.; Garsin, D.A. Enterococcus faecalis Inhibits Hyphal Morphogenesis and Virulence of Candida albicans. Infect. Immun. 2012, 81, 189-200. [CrossRef]

15. Bachtiar, E.W.; Dewiyani, S.; Akbar, S.M.S.; Bachtiar, B.M. Inhibition of Candida albicans biofilm development by unencapsulated Enterococcus faecalis cps. J. Dent. Sci. 2016, 11, 323-330. [CrossRef]

16. Graham, C.; Cruz, M.R.; Garsin, D.A.; Lorenz, M.C. Enterococcus faecalisbacteriocin EntV inhibits hyphal morphogenesis, biofilm formation, and virulence ofCandida albicans. Proc. Natl. Acad. Sci. USA 2017, 114, 4507-4512. [CrossRef]

17. Witzler, J.J.P.; Pinto, R.A.; De Valdez, G.F.; De Castro, A.D.; Cavallini, D.C.U. Development of a potential probiotic lozenge containing Enterococcus faecium CRL. LWT 2017, 77, 193-199. [CrossRef]

18. Heinemann, R.J.; Carvalho, R.A.; Favarotrindade, C.S. Orally disintegrating film (ODF) for delivery of probiotics in the oral cavity-Development of a novel product for oral health. Innov. Food Sci. Emerg. Technol. 2013, 19, 227-232. [CrossRef]

19. Saha, S.; Tomaro-Duchesneau, C.; Daoud, J.T.; Tabrizian, M.; Prakash, S. Novel probiotic dissolvable carboxymethyl cellulose films as oral health biotherapeutics: In vitro preparation and characterization. Expert Opin. Drug Deliv. 2013, 10, 1471-1482. [CrossRef] [PubMed]

20. Lee, Y.; Kim, K.; Kim, M.; Choi, D.H.; Jeong, S.H. Orally disintegrating films focusing on formulation, manufacturing process, and characterization. J. Pharm. Investig. 2017, 47, 183-201. [CrossRef]

21. Dixit, R.P.; Puthli, S.P. Oral strip technology: Overview and future potential. J. Control. Release 2009, 139, 94-107. [CrossRef] [PubMed]

22. Borges, J.; Silva, A.; Cervi-Bitencourt, C.; Vanin, F.; Carvalho, R. Lecithin, gelatin and hydrolyzed collagen orally disintegrating films: Functional properties. Int. J. Biol. Macromol. 2016, 86, 907-916. [CrossRef]

23. de Barros, J.M.; Scherer, T.; Charalampopoulos, D.; Khutoryanskiy, V.V.; Edwards, A.D. A Laminated Polymer Film Formulation for Enteric Delivery of Live Vaccine and Probiotic Bacteria. J. Pharm. Sci. 2014, 103, 2022-2032. [CrossRef] [PubMed] 
24. Heinemann, R.J.B.; Vanin, F.M.; De Carvalho, R.A.; Trindade, M.A.; Fávaro-Trindade, C.S. Characterization of low cost orally disintegrating film (ODF). Polímeros 2017, 27, 48-54. [CrossRef]

25. Nobile, C.J.; Johnson, A.D. Candida albicansBiofilms and Human Disease. Annu. Rev. Microbiol. 2015, 69, 71-92. [CrossRef]

26. Nalluri, B.N.; Sravani, B.; Anusha, S.; Sribramhini, R.; Maheswari, K.M. Development and Evaluation of Mouth Dissolving Films of Sumatriptan Succinate for Better Therapeutic Efficacy. J. Appl. Pharm. Sci. 2013, 3, 161-166. [CrossRef]

27. Prezotti, F.G.; Meneguin, A.B.; Evangelista, R.C.; Cury, B.S.F. Preparation and characterization of free films of high amylose/pectin mixtures cross-linked with sodium trimetaphosphate. Drug Dev. Ind. Pharm. 2012, 38, 1354-1359. [CrossRef]

28. Meneguin, A.B.; Cury, B.; Evangelista, R.C. Films from resistant starch-pectin dispersions intended for colonic drug delivery. Carbohydr. Polym. 2014, 99, 140-149. [CrossRef] [PubMed]

29. Gennadios, A.; Weller, C.; Hanna, M.; Froning, G. Mechanical and Barrier Properties of Egg Albumen Films. J. Food Sci. 1996, 61, 585-589. [CrossRef]

30. Meneguin, A.B.; Cury, B.S.F.; dos Santos, A.M.; Franco, D.F.; Barud, H.S.; Filho, E.C.D.S. Resistant starch/pectin free-standing films reinforced with nanocellulose intended for colonic methotrexate release. Carbohydr. Polym. 2017, 157, 1013-1023. [CrossRef] [PubMed]

31. Bruschi, M.L.; Jones, D.S.; Panzeri, H.; Gremião, M.P.; de Freitas, O.; Lara, E.H. Semisolid Systems Containing Propolis for the Treatment of Periodontal Disease: In Vitro Release Kinetics, Syringeability, Rheological, Textural, and Mucoadhesive Properties. J. Pharm. Sci. 2007, 96, 2074-2089. [CrossRef]

32. Fontana, C.R.; Abernethy, A.D.; Som, S.; Ruggiero, K.; Doucette, S.; Marcantonio, R.A.; Boussios, C.I.; Kent, R.; Goodson, J.M.; Tanner, A.C.R.; et al. The antibacterial effect of photodynamic therapy in dental plaque-derived biofilms. J. Periodontal Res. 2009, 44, 751-759. [CrossRef]

33. Zago, C.E.; Silva, S.; Sanitá, P.V.; Barbugli, P.; Dias, C.M.I.; Lordello, V.B.; Vergani, C.E. Dynamics of Biofilm Formation and the Interaction between Candida albicans and Methicillin-Susceptible (MSSA) and -Resistant Staphylococcus aureus (MRSA). PLoS ONE 2015, 10, e0123206. [CrossRef]

34. Ochwoto, M.; Muita, L.; Talaam, K.; Wanjala, C.; Ogeto, F.; Wachira, F.; Osman, S.; Kimotho, J.; Ndegwa, L. Anti-bacterial efficacy of alcoholic hand rubs in the Kenyan market. Antimicrob. Resist. Infect. Control 2017, 6, 17. [CrossRef] [PubMed]

35. Cavallini, D.C.; Bedani, R.; Bomdespacho, L.Q.; Vendramini, R.C.; Rossi, E.A. Effects of probiotic bacteria, isoflavones and simvastatin on lipid profile and atherosclerosis in cholesterol-fed rabbits: A randomized double-blind study. Lipids Health Dis. 2009, 8, 1-8. [CrossRef] [PubMed]

36. Cavallini, D.C.; Suzuki, J.Y.; Abdalla, D.S.; Vendramini, R.C.; Pauly-Silveira, N.D.; Roselino, M.N.; Pinto, R.A.; Rossi, E.A. Influence of a probiotic soy product on fecal microbiota and its association with cardiovascular risk factors in an animal model. Lipids Health Dis. 2011, 10, 126. [CrossRef] [PubMed]

37. Celiberto, L.; Bedani, R.; Dejani, N.N.; De Medeiros, A.I.; Zuanon, J.A.S.; Spolidorio, L.C.; Adorno, M.A.T.; Varesche, M.B.A.; Galvão, F.C.; Valentini, S.R.; et al. Effect of a probiotic beverage consumption (Enterococcus faecium CRL 183 and Bifidobacterium longum ATCC 15707) in rats with chemically induced colitis. PLoS ONE 2017, 12, e0175935. [CrossRef] [PubMed]

38. Marchesin, J.D.C.; Celiberto, L.S.; Orlando, A.B.; de Medeiros, A.I.; Pinto, R.A.; Zuanon, J.A.S.; Spolidorio, L.C.; dos Santos, A.; Taranto, M.P.; Cavallini, D.C.U. A soy-based probiotic drink modulates the microbiota and reduces body weight gain in diet-induced obese mice. J. Funct. Foods 2018, 48, 302-313. [CrossRef]

39. Meng, X.; Stanton, C.; Fitzgerald, G.; Daly, C.; Ross, R. Anhydrobiotics: The challenges of drying probiotic cultures. Food Chem. 2008, 106, 1406-1416. [CrossRef]

40. Celiberto, L.S.; Bedani, R.; Rossi, E.A.; Cavallini, D.C.U. Probiotics: The Scientific Evidence in the Context of Inflammatory Bowel Disease. Crit. Rev. Food Sci. Nutr. 2015, 57, 1759-1768. [CrossRef]

41. Garsuch, V.; Breitkreutz, J. Comparative investigations on different polymers for the preparation of fast-dissolving oral films. J. Pharm. Pharmacol. 2010, 62, 539-545. [CrossRef]

42. European Pharmacopoeia Commission. Oromucosal preparations. In European Pharmacopoeia, 8th ed.; European Directorate for the Quality of Medicines (EDQM): Strasbourg, France, 2013; pp. 793-796.

43. Preis, M.; Gronkowsky, D.; Grytzan, D.; Breitkreutz, J. Comparative study on novel test systems to determine disintegration time of orodispersible films. J. Pharm. Pharmacol. 2014, 66, 1102-1111. [CrossRef]

44. Welch, K.; Strømme, M. Simultaneous Measurement of Drug Release and Liquid Uptake in Pharmaceutical Tablets. J. Pharm. Sci. 2003, 92, 1242-1249. [CrossRef] [PubMed]

45. Nielsen, L.E. Models for the Permeability of Filled Polymer Systems. J. Macromol. Sci. Part A Chem. 1967, 1, 929-942. [CrossRef]

46. Santos, T.C.; Rescignano, N.; Boff, L.; Reginatto, F.H.; Simões, C.M.O.; de Campos, A.M.; Mijangos, C.U. Manufacture and characterization of chitosan/PLGA nanoparticles nanocomposite buccal films. Carbohydr. Polym. 2017, 173, 638-644. [CrossRef]

47. Carvalho, F.C.; Bruschi, M.L.; Evangelista, R.C.; Gremião, M.P.D. Mucoadhesive drug delivery systems. Braz. J. Pharm. Sci. 2010, 46, 1-17. [CrossRef]

48. Vilela, S.F.; Barbosa, J.O.; Rossoni, R.D.; Santos, J.D.; Prata, M.C.; Anbinder, A.L.; Jorge, A.O.; Junqueira, J.C. Lactobacillus acidophilus ATCC 4356 inhibits biofilm formation by C. albicans and attenuates the experimental candidiasis in Galleria mellonella. Virulence 2014, 6, 29-39. [CrossRef] 
49. Matsubara, V.H.; Wang, Y.; Bandara, H.; Mayer, M.; Samaranayake, L.P. Probiotic lactobacilli inhibit early stages of Candida albicans biofilm development by reducing their growth, cell adhesion, and filamentation. Appl. Microbiol. Biotechnol. 2016, 100, 6415-6426. [CrossRef]

50. Ribeiro, F.; De Barros, P.; Rossoni, R.; Junqueira, J.; Jorge, A. Lactobacillus rhamnosusinhibitsCandida albicansvirulence factorsin vitroand modulates immune system inGalleria mellonella. J. Appl. Microbiol. 2016, 122, 201-211. [CrossRef]

51. Davis, D. Adaptation to environmental $\mathrm{pH}$ in Candida albicans and its relation to pathogenesis. Curr. Genet. 2003, 44, 1-7. [CrossRef] 